\title{
Do Tunnel Patterns of Coptotermes formosanus and Coptotermes gestroi (Blattodea: Rhinotermitidae) Reflect Different Foraging Strategies?
}

\author{
by \\ Nirmala K. Hapukotuwa ${ }^{1} \&$ J. Kenneth Grace ${ }^{1 *}$
}

ABSTRACT

Tunnel network construction and time to food (wood) discovery by Coptotermes formosanus Shiraki and Coptotermes gestroi (Wasmann) (Blattodea: Rhinotermitidae) (formerly known as Coptotermesvastator Light in the Pacific region) was examined when wood was present in a clumped distribution that mimics field conditions in the subtropical and temperate regions where $C$. formosanus naturally occurs. Previous research has noted that the tropical species $C$. gestroi constructs a highly branched tunnel network, while the subtropical $C$. formosanus constructs longer tunnels with few branches. Grace et al. (2004) hypothesized that this difference in tunneling behavior may relate to a more homogenous distribution of woody resources in the tropics vs. a disjunct and clumped distribution of fallen wood in the cooler subtropics. Thus, C. gestroi may exhibit a thorough search of the immediate area where wood is initially located, while it may be more energetically efficient for $C$. formosanus to tunnel greater distances in search of scattered resources. To test this hypothesis, we placed two wood resources at the opposite ends of laboratory foraging arenas, and released 1500 termites (1350 workers: 150 soldiers) into each arena. Arenas were observed every 24 hours for 14 days. We measured the total daily tunnel length, number of tunnels created in each quadrant of the arenas, and average time to discover food at both ends. Total daily tunnel length was relatively longer with $C$. formosanus and average time to discover food at either end was longer for $C$. gestroi. Although replication was limited in this study, these observations lend support to the hypothesis that $C$. formosanus is able to locate distant resources more efficiently than C. gestroi.

${ }^{1}$ College of Tropical Agriculture \& Human Resources, University of Hawaii at Manoa, 3050 Maile Way, Gilmore 202, Honolulu HI 96822, USA

*Corresponding author. Email: kennethg@hawaii.edu 


\section{INTRODUCTION}

The tunneling behavior of subterranean termites is difficult to study due to their cryptic habitat (Puche \& Su 2001b). However, laboratory studies with two-dimensional foraging arenas have provided insight into tunneling geometry (e.g., Puche \& Su 2001a, Campora \& Grace 2001, Bardunias \& $\mathrm{Su}$ 2005, Nobre et al. 2007). Much research has been done in recent years on tunneling behavior in such arenas, including studies on the influence of the presence of wood and/or of wood discovery on tunnel orientation. Campora \& Grace (2001) found that the basic pattern of tunneling by Coptotermes formosanus Shiraki was not influenced by the proximity of wood. Changes in tunneling patterns appeared to reflect physical cues (as anomalies in the substratum) rather than the presence of edible wood. Puche \& Su (2001a) and Nobre et al. (2007) reported similar results in which the presence of wood in the soil did not influence termite tunnel orientation. However, other researchers have demonstrated that tunnel orientation can be influenced by the very close presence of sound or decayed wood (Amburgey and Smythe 1977 Reinhard et al. 1997). Hedlund et al. (1999) found that Formosan subterranean termites exhibited changes in activity when available food size varied; when food size was increased, termite survival rates and food consumption rates also increased. Similar findings were observed by Akhtar \& Jabeen (1981) and Waller (1988). Reinhard \& Kaib (1995) found high feeding rates on large food resources, possibly due to the presence of chemical signals from labial gland secretions.

Laboratory studies of complex behavior are always subject to the possibility of artifacts occurring due to the artificial nature of the bioassay situation. With respect to the use of laboratory arenas to investigate termite tunneling behavior, however, Campora \& Grace (2009) demonstrated by installing identical arenas in the field (connected directly to the soil) that the same tunneling patterns occur in both field and laboratory; although differences in rates of tunneling between different $C$. formosanus colonies were more apparent under field conditions, likely due to the much greater number of termites tunneling through the field arenas.

There have been a limited number of comparative behavioral studies carried out on Coptotermes formosanus and Coptotermes gestroi (Wasmann). 
Coptotermes gestroi was formally known as Coptotermes vastator Light in the Pacific region, until synonymized by Yeap et al (2007). Shelton and Grace (2003) noted higher mortality rates of $C$. gestroi than of $C$. formosanus under desiccating conditions. Uchima \& Grace (2003), Grace et al. (2004) and Hapukotuwa \& Grace (2011b) reported that $C$. formosanus generally has a higher wood feeding rate than C. gestroi. Uchima \& Grace (2009) reported that $C$. gestroi had higher mortality rates in interspecific agonism and foraging competition experiments with C. formosanus. Grace et al. (2004) documented by visual observations that the tunnel systems of $C$. gestroi are distinctly different from those of $C$. formosanus. Coptotermes gestroi makes long, thin, highly branched tunnels; whereas $C$. formosanus constructs longer, wider, and lessbranched tunnels. These visual observations were subsequently quantified by Hapukotuwa \& Grace (2010, 2011a).

The objectives of the present study were to evaluate the tunneling systems of $C$. formosanus and C. gestroi and the time to food location when food (wood) was present in the foraging arena as a discrete, clumped resource. As mentioned, Grace et al. (2004) and Hapukotuwa \& Grace (2010, 2011a) demonstrated that the tropical species $C$. gestroi constructs a highly branched tunnel network over a fairly limited area, while the subtropical $C$. formosanus constructs longer and wider tunnels with few branches. Grace et al. (2004) hypothesized that this difference in foraging behavior may be related to foraging efficiency in the tropical vs. subtropical environs. Woody resources would be expected to have a generally homogenous distribution in the tropics, as opposed to the more disparate and clumped distribution of such resources further from the equator in the subtropical and temperate regions. Thus, an efficient foraging strategy for the tropical C. gestroi would be to conduct an intensive local search of the immediate area where food (wood) is first found. In contrast, the subtropical $C$. formosanus may have to travel greater distances in search of discrete, scattered (or clumped) resources. The highly branched tunnel network of C. gestroi, and the longer, unbranched tunnels of $C$. formosanus appear to demonstrate these two different foraging strategies, each of which is most efficient for the particular environment inhabited by each termite species. Although both species are distributed around the globe, they are only known to occur together in Taiwan, Florida, and Hawaii, offering a unique opportunity in Hawaii to directly compare their foraging strategies. 
We chose to simulate the clumped distribution of wood in the subtropical and temperate regions by placing wood at opposite ends of a square foraging arena. The time taken to locate food at each end of the arena after release of either $C$. formosanus or $C$. gestroi in the center of each arena represents a measure of the efficiency of the foraging (tunneling) strategy of each species under these pseudo-subtropical conditions of clumped woody resources. Support for the hypothesis offered by Grace et al. (2004) would be demonstrated by more rapid food location, particularly of the second resource to be found, by C. formosanus, the subtropical species with longer and generally unbranched tunnels. Under the conditions of this experiment, the tropical C. gestroi would be expected to spend more time in local search, constructing a densely branched network of fine tunnels, particularly once food was initially discovered; and would be expected to be slower to locate the separated resources, particularly the second resource to be found.

\section{MATERIALS AND METHODS}

\section{Test Arenas}

We used six test arenas, three for C.formosanus and three for C. gestroi. All test arenas consisted of two sheets of transparent acrylic. The upper half was $85 \times 85 \times 0.25 \mathrm{~cm}$ and the lower half was $85 \times 85 \times 0.50 \mathrm{~cm}$. Each half was fixed together using metal screws to create a space of $75 \times 75 \times 0.25 \mathrm{~cm}$ in the middle. On the inner space of the lower half, eight small squares with screw holes were affixed to the bottom of the lower half to keep the space uniform after assembly. The upper half of the arena had one chamber (termite release chamber, $8.5 \mathrm{~cm}$ in diameter) in the center. Two pre-weighed Douglas fir (Pseudotsuga menziessii) wood blocks $(2.5 \times 2.0 \times 0.5 \mathrm{~cm})$ were placed at each of the two corners of each arena (Fig. 1), representing separated and clumped food resources for the termites.

The space between the acrylic seats was filled with silica sand (40-100 mesh, 150-425 $\mu \mathrm{m}$ sieve, Fisher Scientific, Fair Lawn, NJ) moistened with de-ionized water (approximately $18 \%$ by weight) (Campora \& Grace 2004). Sand was spread manually and as far as possible evenly across the arena with no space left between the lid and the sand surface (Nobre et al. 2007). A wet filter paper was placed in the center termite release jar to provide initial food and moisture. All arenas were placed on a metal frame supported by glass jars 


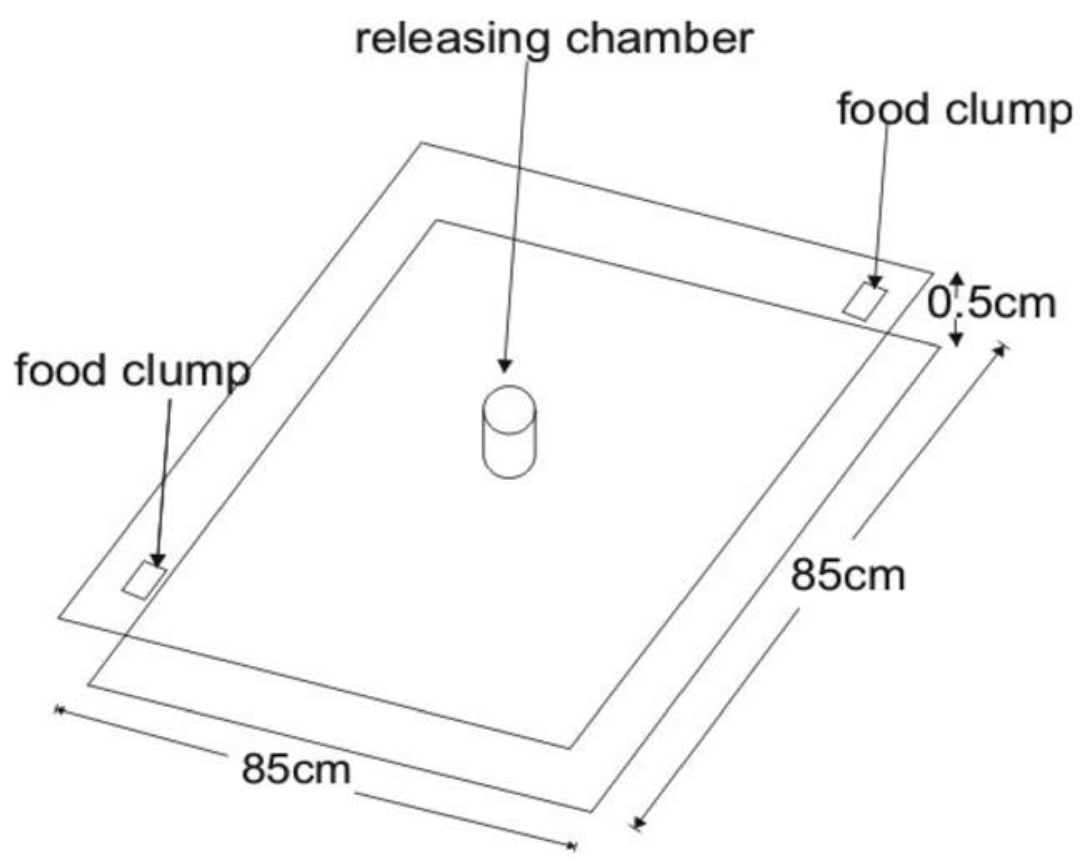

Fig. 1. Schematic drawing of the termite foraging arena.

and kept in a dark room. Fluorescent lights were placed under each arena to observe tunneling patterns and to take photographs.

\section{Termites and Bioassays}

Coptotermes formosanus were collected from a site on the Manoa campus of the University of Hawaii (Irradiator colony; $21^{\circ} 17^{\prime} \mathrm{N} ; 157^{\circ} 99^{\prime} \mathrm{W}$; $23.1 \mathrm{~m}$ above sea level). C. gestroi was collected from Kalaeloa, a field site on the west side of Oahu, Hawaii, $40 \mathrm{~km}$ from the University of Hawaii at Manoa campus (Barber's Point Horse Stables; $21^{\circ} 19^{\prime}$ N; $158^{\circ} 02^{\prime}$ W; 9 m above sea level).

Termites were collected in wood within aggregation traps (Tamashiro et al. 1973) at each site. Termites were extracted from the wood and counted using techniques modified from those of Tamashiro et al. (1973), Su \& La Fage 
(1984), and Grace et al. (1995). We used 1500 termites comprised of $90 \%$ workers and $10 \%$ soldiers for each arena ( 1350 workers: 150 soldiers). A subset of 40 workers of each termite species was weighed before being added to the arenas. Finally, termites were transferred to each arena's central releasing chamber.

Arenas were observed daily (every 24 hours) over 14 days. Temperature and humidity were recorded using an indoor data logger (HOBO U10 Temp/RH Data Logger). Tunnel patterns were photographed daily using a Nikon 12.3 MP digital camera.

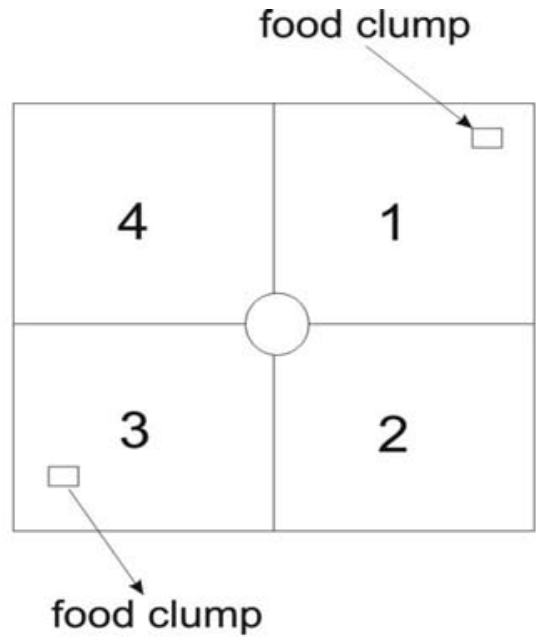

Fig. 2. Division of the foraging arena into four sectors.

\section{Analyses}

The digital camera images were used to determine daily tunnel lengths (primary, secondary, tertiary and other) using Adobe Acrobat Professional 8 software. In addition, to test if there was greater tunneling activity in the vicinity of the food sources once they were found by the termites, each digitized image was divided into four equal sectors (Fig. 2) and the number of tunnels was counted in each sector.Statistical analyses were carried out using SAS 9.2 software. A general linear model (one-way ANOVA) and Ryan-EinotGabriel-Welsch Multiple Range Test were used with total tunnel length per day (within each observation time) to test for differences in tunnellength over time between the two species $C$. formosanus and $C$. gestroi. Student's $t$-test was used to compare the frequency of tunnels in each sector to detect any differences in tunnel number with or without food present (for total length of the tunnels per sector relative to the total tunnel length per arena). Mean wood consumption rates were calculated using initial and final dry weights of all wood blocks for each termite species. 

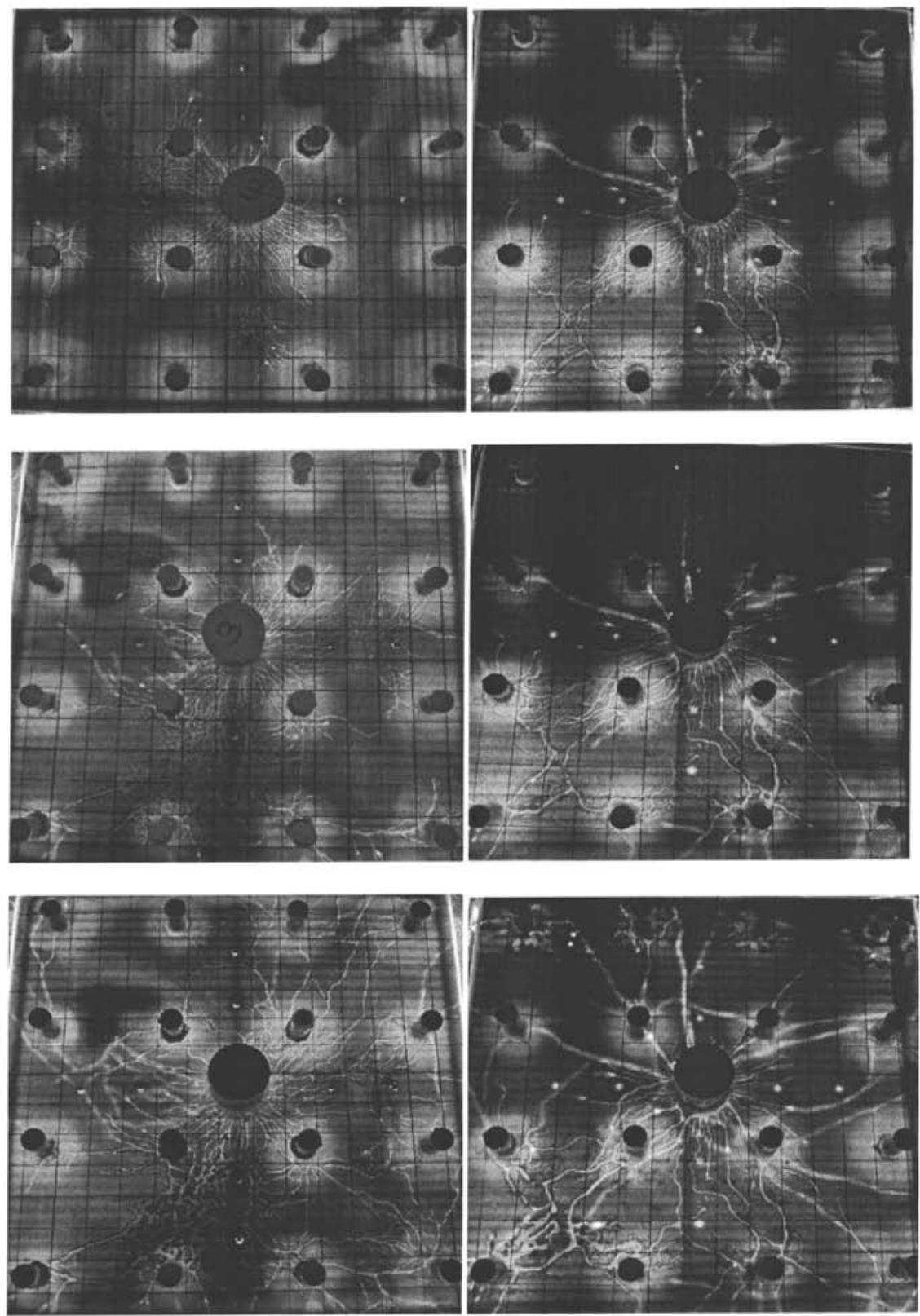

Fig.3. Representative foraging arenas containing C. gestroi (left) and C.formosanus (right) on day 3 (top), day 4 (center), and day 14 (bottom). 
Table 1: Total number of tunnels in each section of foraging arenas (numbers in parentheses are ratio of number of tunnels in each section to total tunnel number of tunnels in the entire arena).

\begin{tabular}{lllllll}
\hline \hline Termite species & $\begin{array}{l}\text { No. of } \\
\text { tunnels } \\
\text { in sec. 1 }\end{array}$ & $\begin{array}{l}\text { No. of } \\
\text { tunnels } \\
\text { in sec. 2 }\end{array}$ & $\begin{array}{l}\text { No. of } \\
\text { tunnels } \\
\text { in sec. 3 }\end{array}$ & $\begin{array}{l}\text { No. of } \\
\text { tunnels } \\
\text { in sec. 4 }\end{array}$ & $\begin{array}{l}\text { Total no. of } \\
\text { tunnels in } \\
\text { arena }\end{array}$ & $\begin{array}{l}\text { Surviving } \\
\text { termites } \\
\text { (w:soldiers) }\end{array}$ \\
\hline C.formosanus & $23(0.29)$ & $20(0.25)$ & $24(0.30)$ & $13(0.16)$ & 80 & $728: 89$ \\
C.formosanus & $25(0.19)$ & $36(0.27)$ & $48(0.36)$ & $23(0.17)$ & 132 & $743: 101$ \\
C. gestroi & $52(0.24)$ & $60(0.28)$ & $80(0.37)$ & $23(0.11)$ & 215 & $690: 90$ \\
C. gestroi & $23(0.23)$ & $19(0.19)$ & $28(0.28)$ & $29(0.29)$ & 99 & $746: 92$ \\
\hline \hline
\end{tabular}

\section{RESULTS}

\section{Behavioral Observations}

We observed both similarities and differences in the tunneling and other foraging activities of C. formosanus and C. gestroi. On the first day after release (after 12 hours) most of the termites (nearly 75\%) remained in the central release chamber, with the remainder starting to make tunnels outward. From the $2^{\text {nd }}$ to $8^{\text {th }}$ day, both species were very active and constructed large numbers of tunnels throughout the arenas. As previously noted, C. formosanus made fewer, less branched, and longer tunnels; while C. gestroi constructed a larger number of highly branched tunnels (Fig 3). The species demonstrated some common behaviors, such as moving back and forth, tunnel excavation, and resting in groups. During the last few days of the experiment (from day 9 to 14), activity of both termite species was greatly reduced. Most gathered in small groups, while others moved very slowly. Also, during the last few days the number of dead termites observed in the arenas was greater for both species than in the earlier days. During the experiment, temperature ranged from $23^{\circ} \mathrm{C}$ to $24^{\circ} \mathrm{C}$ and relative humidity ranged from $57 \%$ to $64 \%$.

Both termite species were able to find the food (wood) on both sides of the arena over the course of the experimental period. However, they exhibited different time frames for discovery (Fig. 4). For example, $C$. formosanus in arena no. 4 found wood in one side of the arena during the $2^{\text {nd }}$ day and on other side on the $8^{\text {th }}$ day; and in arena no. 5 found wood on one side on the $3^{\text {rd }}$ day and on other side during the $4^{\text {th }}$ day. Coptotermes gestro $i$ in arena no. 3 found wood on one side on the $3^{\text {rd }}$ day and on the other side on the $8^{\text {th }}$ day; and in arena no. 1 found wood on the first side during the $4^{\text {th }}$ day and 
on the other side on the $9^{\text {th }}$ day. Two other arenas (no. 2 for $C$. gestroi and no. 6 for $C$. formosanus) had to be discarded discarded because of warped upper covers on the arenas. Due to this bending, it was impossible to see any tunnels; and there was a space between the upper and lower layers through which termites could move. With the two arenas remaining for each termite species (total of four arenas), the average time to discover wood initially was 2.5 days for $C$. formosanus, and 3.5 days for C. gestroi. Following this initial discovery, the average time to discover the wood on the opposite side of the arena was 6 days with $C$. formosanus, and 8.5 days with $C$. gestroi. Thus, although replication is limited, the longer time taken for wood discovery by $C$. gestroi, and particularly for discovery of the second wood resource, supports the hypothesis presented by Grace et al. (2004) that the tunneling pattern of C. formosanus is optimized for the more disjunct and clumped distribution of wood resources found further from the equator.

\section{Statistical Analyses}

Overall, tunneling rates of both species did not differ significantly $(D F=01$, $F=0.34, P=0.5649)$. However, total tunnel length was relatively greater for $C$. formosanus than for C. gestroi (Fig. 5). Coptotermes gestroi constructed a larger number of secondary and tertiary tunnels compared to C. formosanus.

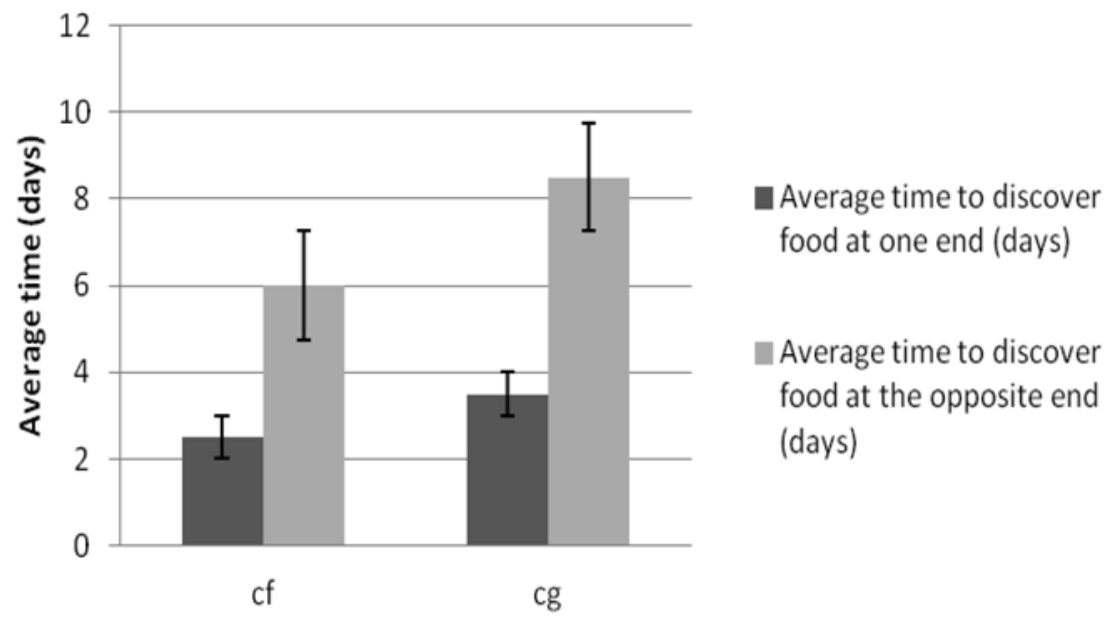

Fig. 4. Average time to discover food at both ends of arenas for C. formosanus (cf) and C. gestroi (cg). 
Total tunnel numbers in each section of the arena (two sections with wood and two sections without wood) were not significantly different $(t$ value $=0.9$, $D F=4, P=0.42)$. Neither the total number of tunnels at the conclusion of the study in sections of the arena with wood present $(D F=1, F=0.55, P=0.536)$, nor the total tunnel number of tunnels in each section without wood differed significantly between the two species $(D F=1, F=0.8, P=0.465)$ (Table 1).

Total wood consumption rates were also not significantly different between the two termite species in this study $(D F=1, F=1.24, P=0.2752)$, although mean mass loss values for $C$. formosanus in each arena were relatively higher than those for C. gestroi (Fig. 6).

Mean percentage mortality values were also not significantly different between the two termite species $(D F=1, F=0.45, P=0.571)$, although $C$. gestroi suffered relatively greater mortality than $C$. formosanus, especially in arena no. 1 (Fig. 7 ).

\section{DISCUSSION}

Due to the unexpected loss of two of the six tunneling arenas used in this study, and the resulting limited replication, we were unable to statistically validate the hypothesis of Grace et al. (2004) that the tunnel patterns of $C$. formosanus and C. gestroi reflect different foraging strategies that are tuned

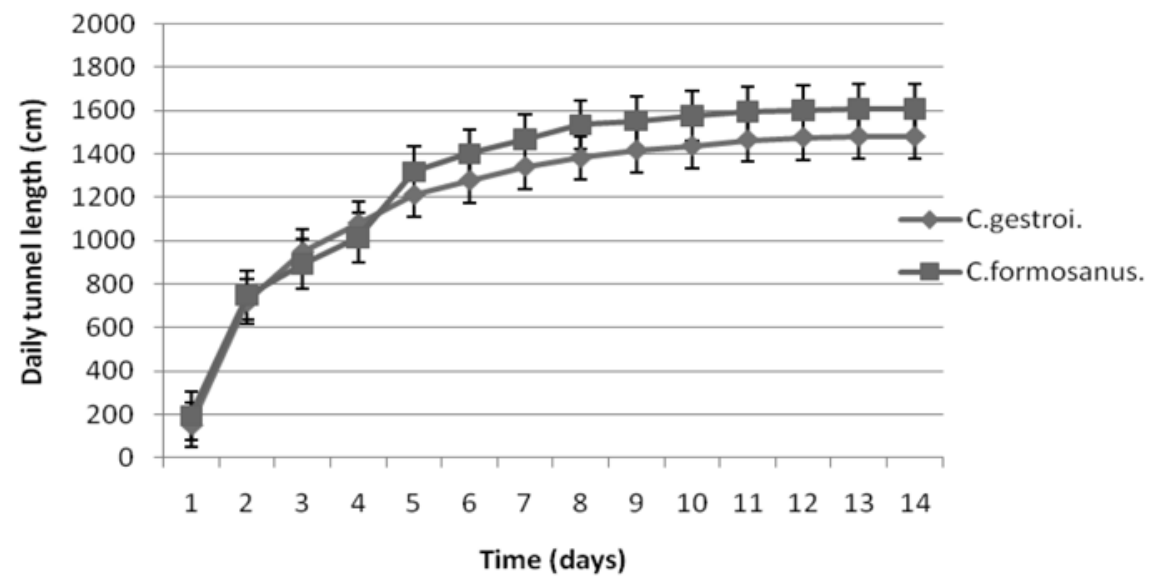

Fig. 5. Daily tunnel lengths for $C$. formosanus and C. gestroi over 14 days (termite species comparison by one-way ANOVA and Ryan-Einot-Gabriel-Welsch Multiple Range Test, $P=0.565$ ). 
to the relative distribution of woody resources in subtropical/temperate vs. tropical environments. However, the more rapid discovery of both the first and second woody resources by $C$. formosanus (Fig. 4) is consistent with this hypothesis.

Tunnel numbers at the conclusion of the study were not significantly different between the two termite species in arena quadrants where wood was present or quadrants where wood was absent. Other authors have observed that the proximity of wood did not influence tunnel patterns for workers of

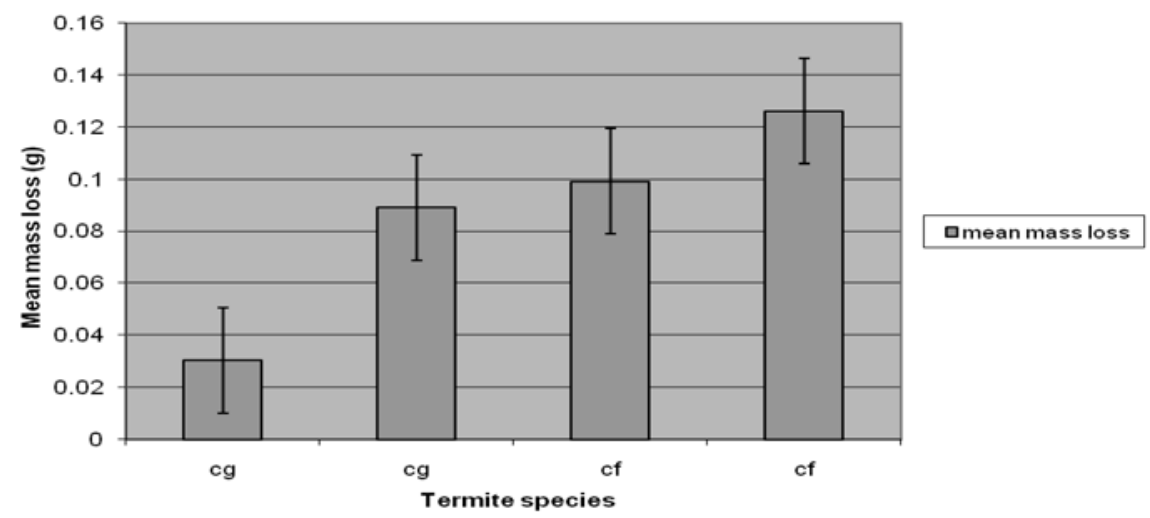

Fig. 6. Mean mass loss values of wood in arenas with either $C$. formosanus or $C$. gestroi (one-way ANOVA, $P=0.275$ )

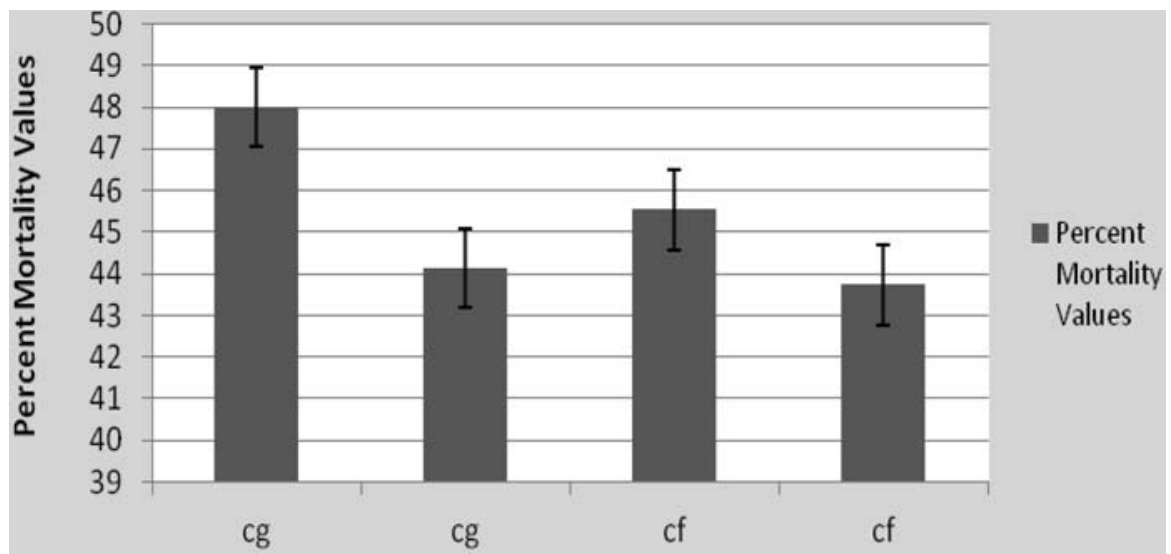

Fig. 7. Percent mortality of C. formosanus and C. gestroi during the bioassay (one-way ANOVA, $P=0.571$ ). 
C. formosanus (Campora \& Grace 2001), Reticulitermesflavipes (Puche\& Su 2001b), and R. grassei (Nobre (2007). These findings are somewhat different from those of Hedland \& Henderson (1999), Akhtar \& Jaben (1981), and Waller (1988) who noted that tunnel numbers increased as the size of the proximate food resource increased.

We observed the same interspecific differences in tunneling patterns noted by Grace et al. (2004) and Hapukotuwa \& Grace (2010, 2011a). Although we were not able to directly relate these tunnel patterns (in terms of tunnel numbers and lengths) to differences in resource usage, the differences in times to locate food noted in this study support the hypothesis of Grace et al. (2004) that C. formosanus is able to locate distant resources more efficiently than $C$. gestroi. This difference is not yet fully resolved, as a result of the limited replication in the present study. However, the results obtained are consistent with the view that the tunneling behavior of $C$. formosanus is energetically more efficient when resources are distant and clumped, as in the subtropics and temperate regions, then the heavily branched, intensive local search strategy employed by the tropical C. gestroi. Future work might employ larger foraging arenas and/or incorporation of a wood distribution pattern to mimic the more homogenous tropical situation.

\section{ACKNOWLEDGMENTS}

We are grateful to R. Oshiro and M. Aihara-Sasaki for technical assistance; and to J. R. Yates III, and M. G. Wright for reviewing early drafts of the manuscript. Thanks are also due to C. Campora for providing us with assistance in arena construction, and to NH's husband, Chaminda Wijesundara, for his help in various ways. Funding for this research was partially provided by USDA-ARS Specific Cooperative Agreements 58-6615-9-200 and 58-6435-8-294; and McIntire-Stennis and Hatch funds administered by the College of Tropical Agriculture and Human Resources, University of Hawaii at Manoa.

\section{REFERENCES}

Akhtar, M.S. \& M.Jabeen. 1981. Influence of specimen size on the amount of wood consumed by termites. Pakistan Journal of Zoology 13: 79-84.

Amburgey, T. L.\& R. V. Smythe. 1977. Factors influencing termite feeding on brown-rotted wood. Sociobiology 3: 3-12. 
Bardunias, P. \& N.-Y. Su. 2005. Comparison of tunnel geometry of subterranean termites (Isoptera: Rhinotermitidae) in "two dimensional" and "three dimensional" arenas. Sociobiology 45: 679-685

Campora, C. E. \& J. K. Grace. 2001. Tunnel orientation and search pattern sequence of the Formosan subterranean termite (Isoptera: Rhinotermitidae). Journal of Economic Entomology 94: 1193-1199.

Campora, C. E. \& J. K. Grace. 2004. Effect of average worker size on tunneling behavior of Formosan subterranean termite colonies. Journal of Insect Behavior 17: 777-791.

Campora, C. E. \& J. K. Grace. 2009. Comparison of tunneling in the laboratory and field by the Formosan subterranean termite, Coptotermesformosanus (Isoptera: Rhinotermitidae). Sociobiology 53: 389-401.

Grace, J. K., M. Aihara-Sasaki \& J. R. Yates. 2004. Differences in tunneling behavior of Coptotermes vastator and Coptotermes formosanus (Isoptera: Rhinotermitidae). Sociobiology 43: 153-158.

Grace, J. K., R. T. Yamamoto \& M. Tamashiro. 1995. Relationship of individual worker mass and population decline in a formosan subterranean termite colony (Isoptera: Rhinotermitidae). Environmental Entomology 24: 1258-1262.

Hapukotuwa, N. K. and J. K. Grace. 2010. Comparative study of tunneling and feeding preferences of Coptotermes formosanus Shiraki and Coptotermes gestroi (Wasmann) (Isoptera: Rhinotermitidae) in foraging arenas. Proceedings of the 2010 National Conference on Urban Entomology. Pp. 33-36.

Hapukotuwa, N. K. \& J. K. Grace. 2011a. Comparative study of tunneling behavior of Coptotermesformosanus Shiraki and C. gestroi (Wasmann) using foraging arenas. Psyche. ISSN 1687-7438, doi:10.1155/PSYCHE. In Review.

Hapukotuwa, N. K. \& J. K. Grace. 2011b. Preferences of Coptotermes formosanus Shiraki and Coptotermes gestroi (Wasmann) (Blattodea: Rhinotermitidae) among three commercial wood species. Insects. ISSN 2075-4450, www.mdpi.com/journal/insects/. In Press.

Hedlund,J.C. \& G. Henderson. 1999. Effect of available food size on search tunnel formation by the Formosan subterranean termite (Isoptera: Rhinotermitidae). Journal of Economic Entomology 92: 610-616.

Nobre, T., L. Nunes \& D. E. Bignell. 2007. Tunnel geometry of the subterranean termite Reticulitermes grassei (Isoptera: Rhinotermitidae) in response to sand bulk density and the presence of food. Insect Science 14: 511-518. doi: 10.1111/j.17447917.2007.00180.x

Puche, H.\&N.-Y.Su. 2001a. Application of fractal analysis for tunnel systems of subterranean termites (Isoptera : Rhinotermitidae) under laboratory conditions. Environmental Entomology 30: 545-549.

Puche, H. \& N.-Y. Su. 2001b. Tunnel formation by Reticulitermes flavipes and Coptotermes formosanus (Isoptera: Rhinotermitidae) in response to wood in sand. Journal of Economic Entomology 94: 1398-1404.

Reinhard, J., H. Hertel \& M. Kaib. 1997. Systematic search for food in the subterranean termite Reticulitermes santonensis De Feytaud (Isoptera, Rhinotermitidae). Insectes 
Sociaux 44: 147-158.

Reinhard, J. \& M. Kaib. 1995. Interaction of pheromones during food exploitation by the termite Schedorhinotermes lamanianus. Physiological Entomology 20: 266-272.

Shelton, T. G. \& J. K. Grace. 2003. Comparative cuticular permebility of two species of Coptotermes Wasmann (Isoptera: Rhinotermitidae). Comparative Biochemistry and Physiology Part A: Molecular and Integrative Physiology 134: 205-211.

Su, N.-Y. \& J. P. La Fage. 1984. Comparison of laboratory methods for estimating wood consumption rates by Coptotermes formosanus Isoptera Rhinotermitidae. Annals of the Entomological Society of America 77: 125-129.

Tamashiro, M.,J.K. Fujii \& P. Y.Lai. 1973. A simple method to observe, trap and preparelarge numbers of subterranean termites for labratory and field experiments. Environmental Entomology 2: 721-722.

Uchima, S. Y. \& J. K. Grace. 2003. Compartive feeding rates of Coptotermes vastator and Coptotermes formosanus (Isoptera: Rhinotermitidae). Sociobiology 41: 289-294.

Uchima, S. Y. \& J. K. Grace. 2009. Interspecific agonism and foraging competition between Coptotermes formosanus and Coptotermes gestroi (Blattodea: Rhinotermitidae). Sociobiology 54: 765-776.

Waller, D. A. 1988. Host selection in subterranean termites: Factors affecting choice (Isoptera,Rhinotermitidae). Sociobiology 14: 5-13.

Yeap, B.-G., A. S. Othman, V. S. Lee \& C.-Y. Lee. 2007. Genetic relationship between Coptotermes gestroi and Coptotermes vastator (Isoptera: Rhinotermitidae). Journal of Economic Entomology 100: 467-474.

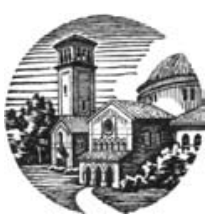

